\title{
Influence of problematic child-teacher relationships on future psychiatric disorder: population survey with 3-year follow-up
}

\author{
Iain A. Lang, * Ruth Marlow, * Robert Goodman, Howard Meltzer and Tamsin Ford
}

\section{Background}

Teacher-pupil relationships have been found to mediate behavioural, social and psychological outcomes for children at different ages according to teacher and child report, but most studies have been small.

\section{Aims \\ To explore later psychiatric disorder among children with problematic teacher-pupil relationships.}

\section{Method}

Secondary analysis of a population-based cross-sectional survey of children aged 5-16 with a 3-year follow-up.

\section{Results}

Of the 3799 primary-school pupils assessed, 2.5\% of parents reported problematic teacher-pupil relationships; for secondary-school pupils $(n=3817)$ this rose to $6.6 \%$. Among secondary-school pupils, even when children with psychiatric disorder at baseline were excluded and we adjusted for baseline psychopathology score, problematic teacher-pupil relationships were statistically significantly related to higher levels of psychiatric disorder at 3-year follow-up (odds ratio $(\mathrm{OR})=1.93,95 \% \mathrm{Cl}$ 1.07-3.51 for any psychiatric disorder, $\mathrm{OR}=3.00,95 \% \mathrm{Cl}$ 1.37-6.58 for conduct disorder). Results for primary-school pupils were similar but non-significant at this level of adjustment.

\section{Conclusions}

This study underlines the need to support teachers and schools to develop positive relationships with their pupils.

\section{Declaration of interest}

None.
Positive and supportive relationships promote healthy child development and resilience, ${ }^{1}$ including those formed within school. Many qualified teachers' report insufficient training in the management of socioemotional and behavioural difficulties, which they cite as a common source of stress and burnout. ${ }^{2}$ Although teachers are highly aware of the importance of the teacher-pupil relationship, some children can be very challenging to work with. The potential impact of adverse teacher-pupil relationships on the health and well-being on the child, their teacher and their peers is not often discussed explicitly, but is important as school-based problems are a common cause for referral to child mental health services. Teachers' assessments of closeness and conflict in their relationships with children may be associated with pupils' subsequent ability to acquire social and academic skills. ${ }^{3}$ Hughes $\& \mathrm{Kwok}^{4}$ showed that higher-quality teacher-pupil relationships attenuate the associations between children's background characteristics and their levels of classroom engagement; the latter mediates academic performance. A positive teacher-pupil relationship can moderate the associations between temperament and disruptive play, and with risky behaviour. ${ }^{5}$ Children with developmental vulnerabilities have better educational outcomes when they receive strong emotional and instructional support in the classroom. ${ }^{6}$

Conversely, unsupportive relationships may impair development and amplify psychosocial problems and psychological distress. ${ }^{7}$ There is evidence that problematic teacher-pupil relationships are stronger predictors of later school-related adjustment than positive relationships. ${ }^{8}$ A study of over 3500 children followed from first to the third grade reported that children's psychosocial adjustment was associated with teachers' relationships with individual children and average classroom levels of teacher-child

*These authors contributed equally to the work. conflict and closeness. ${ }^{9}$ Academic and behavioural problems as far ahead as the eighth grade may be predicted by negative teacher-pupil relationships in kindergarten. ${ }^{10}$ Similar findings have been reported in older children. ${ }^{11}$ Teachers report that they need to provide higher levels of support and more behavioural regulation for children with whom they perceive that they have poor relationships. ${ }^{12}$ A number of factors have been identified as associated with quality of teacher-pupil relationships, such as challenging behaviour and learning difficulties. ${ }^{10}$ Less conflictual relationships are reported with female pupils, ${ }^{13}$ whereas boys have been shown to be more vulnerable to the negative effects of problematic relationships. ${ }^{8,14}$ Teacher-pupil ethnic differences are associated with difficulties in the relationship between teachers and pupils. ${ }^{4,14}$ There is less closeness reported in relationships with children who are shy, ${ }^{11}$ and lower-quality relationships with greater instability were found with children with intellectual disability compared with a control group with typical cognitive development, primarily due to differences in behavioural problems and social skills. ${ }^{15}$ Relationships are reciprocal and teachers struggling to manage children who are behaviourally challenging with insufficient support may have more difficulty establishing a positive relationship with those children than with other children. Teacher-rated problem behaviours only account for half of the variance in problematic teacher-pupil relationships. ${ }^{16}$

In the most extreme cases, problematic teacher-pupil relationships may shade into bullying. Most research on bullying focuses on schoolchildren's peers, ${ }^{17}$ and there is limited information available about the extent and consequences of bullying of pupils by teachers, partly because it is extremely difficult to study. Over $40 \%$ of high-school pupils in a South Australian study reported having been 'picked on' by teachers. ${ }^{18}$ A cross-sectional survey of Israeli pupils reported that just over a quarter of pupils reporting emotional mistreatment by school staff, $12-15 \%$ reporting some form of physical maltreatment and 7-8\% 
reporting sexual maltreatment; ${ }^{19}$ rates that seem startlingly high. Perceived psychological abuse by teachers is an important component of children's school-related stress ${ }^{20}$ and a retrospective survey of college pupils found almost two-thirds reported their worst school experience involved a teacher rather than a peer. ${ }^{21}$ Pupils who feel victimised by teachers and other school staff are more likely to misbehave or to become alienated or aggressive, have less intention of completing school and are likely to engage in high-risk behaviours such as gambling, drug use, and drinking alcohol. ${ }^{18}$ In conclusion, studies using a variety of methods suggest a clear relationship between teacher-pupil relationships and psychosocial and educational outcomes for the child. The current study aimed to assess the psychosocial effects on pupils of a problematic teacher-pupil relationship in a large, nationally representative, general population sample of school-age pupils in Great Britain, followed up after 3 years. We hypothesised that a problematic teacher-pupil relationship would increase pupils' subsequent likelihood of being excluded from school, of having a poor attendance record, of poor family function and the presence of psychiatric disorder.

\section{Method}

In Great Britain, 'child benefit' was a universal state benefit payable for each child in the family, which has almost complete uptake. The British Child and Adolescent Mental Health Survey $(2004)^{22}$ used the child benefit register to develop a sampling frame of postal sectors from Great Britain. The sample included children aged 5-16 living in private households but excluded children who were looked after. In total, 10496 families were approached in relation to one child between January to June 2004, of whom $76 \%$ (7977) responded. Of these, 67\% (5326) took part in a 3-year follow-up between January and June in 2007; loss to follow-up was more common among children who were older, children who did not live with both biological parents, children from larger families and children who had higher levels of psychopathology.

\section{Measures}

\section{Exposure: teacher-pupil relationship}

Parents were asked 'over the last year, has (their child) been stressed because $s /$ he feels $s /$ he has been unfairly picked on by a teacher?' Responses were: no, a little or a lot. We report the prevalence of each response. We have no data that would allow us to check the veracity of the parental report, or to ascertain whether the child was either stressed and/or picked on. A parental report of 'a lot' would seem to indicate a significantly problematic teacher-pupil relationship, regardless of whether the parent is referring to the severity of their child's distress and/or a belief that their child is being unfairly picked on. Multivariable analyses, therefore, took 'a lot' to indicate problems within the teacherpupil relationship, as contrasted with the other two categories combined, whereas descriptive analysis assumed that a response of 'no' indicated no difficulties, and a response of 'a little' indicated possible problems.

\section{Outcomes: child mental health/well-being}

The Development and Well-Being Assessment (DAWBA) assessed the presence of psychiatric disorder at the point of data collection in both surveys. $^{23}$ In the validation study, the DAWBA discriminated well between community and clinical samples. ${ }^{23}$ There were high levels of agreement between the DAWBA and case notes among the clinical sample (Kendall's tau $b=0.47-0.70$ ). This structured interview was administered by lay interviewers to the parents or carers of all children, and to children aged 11 or over. Interviewers recorded detailed verbatim descriptions of any problem areas. An abbreviated version was mailed to the child's teacher. A small team of experienced clinicians used the information provided by all the informants, combining information as they would in the clinic, to make diagnoses according to DSM-IV criteria. ${ }^{24}$ The kappa statistic for chancecorrected agreement on 500 children between two raters was 0.86 for any disorder, 0.57 for emotional disorders and 0.98 for behavioural disorders. ${ }^{23}$

Parents completed the Strengths and Difficulties Questionnaire (SDQ), a 25-item dimensional measure of psychopathology, which has been shown to have good reliability, internal consistency and convergent validity with comparable scales on the Child Behavior Checklist. ${ }^{25}$ The General Functioning Scale of the McMaster Family Assessment Device (FAD) was administered to all parents during the 2004 survey. The FAD questionnaire measures family functioning and consist of 12 items, such as; 'we confide in each other' and 'we are accepted for who we are.. ${ }^{26}$ An overall score of family functioning is given ranging from one to three, with a cut-point of two taken to indicate unhealthy family functioning. The measure has been shown to have good reliability, internal consistency and validity in distinguishing between non-clinical families and families attending a psychiatric service. ${ }^{26}$ The Family Life Questionnaire (FaLQ) was used to assess family function during the 2007 survey. It is a 14-item questionnaire comprising four theoretical scales: affirmation, discipline, special allowances and rules. ${ }^{27}$

\section{Other variables}

In our full model we adjusted for the following potential confounders collected at baseline: gross weekly household income (split into eight categories by 100s of pounds sterling); housing tenure (owned/rented); mother's highest educational qualification (none; poor GCSE or equivalent; A level or good GCSE; diploma or degree); parental symptoms of anxiety and/or depression (12-item version of the General Health Questionnaire (GHQ-12) score; ${ }^{28}$ child's score on social aptitudes scale; level of intellectual disability (none; borderline; moderate or severe); and parental report of the child's general health (very good or good, fair, bad, or very bad). We did not adjust for the ethnicity of the child as it was not associated with poor teacher-pupil relationships at baseline, which was reported by $4.7 \%$ of parents of children who were White, $3.3 \%$ of children who were Black African or African-Caribbean, 2.4\% of Indian children, 3.3\% of Bangladeshi/Pakistani children and $4.0 \%$ of children of mixed/ other ethnicity $\left(\chi^{2}=9.9\right.$, d.f. $\left.=8, P=0.27\right)$.

\section{Analysis}

Data analysis used Stata (SE 11) on Windows and logistic regression for binary outcomes and linear regression for linear outcomes. Analyses were weighted using probability weights calculated by the original survey team (see Green et al, ${ }^{22}$ technical report) that were calculated to represent the age, gender and region structure of the sampling frame and to correct for unequal sampling probabilities of postcodes. Given the increase in prevalence of problematic teacher-pupil relationships with age and given that primary and secondary schools function very differently, multivariable analyses were completed separately for primaryand secondary-school pupils, for each of the following outcomes at 3-year follow-up: any psychiatric disorder, conduct disorder, parental psychopathology (GHQ score), exclusion, non-exclusionary absence and poor family function. We conducted separate analyses 
that adjusted for, or excluded, children with a psychiatric disorder at baseline, and that did, or did not, adjust for baseline symptom scores on the SDQ in order to control for the impact that existing psychopathology might have on teacher-pupil relationships.

\section{Results}

Reassuringly, the majority of parents believed that there was no difficulty in the relationship between their child and their teacher (online Table DS1). Of 3799 parents of primary schoolchildren, $94(2.5 \%)$ stated that they thought their child was distressed because s/he was being picked on by a teacher 'a lot', which increased among secondary-school pupils to 252 out of 3817 $\left(6.6 \% ; \chi^{2}(1)=70, P<0.001\right)$. Online Table DS1 also illustrates the distribution of child and family characteristics among the participants of the baseline survey, and Table 1 indicates the distribution of outcomes at follow-up. A slightly lower proportion of children whose parents reported a poor teacher-pupil relationships participated in the follow-up $(60 \% ; n=208)$ compared with the rest of the sample (67\%).

Tables 2 and 3 show the adjusted multivariable analyses of the association between the teacher-pupil relationships and adverse psychosocial outcomes for primary-school (Table 2) and secondary-school (Table 3) pupils. Problematic teacher-pupil relationships significantly increased odds of any psychiatric disorder and any conduct disorder 3 years later in both age groups, even when controlling for and excluding baseline psychiatric disorder. However, the association became nonsignificant among primary schoolchildren when baseline SDQ total difficulties score was also controlled. Adjusting for baseline SDQ total difficulties disorder also reduced other possibly important associations below the level of statistical significance: these were between poor teacher-pupil relationships and exclusion from secondary school and poor teacher-pupil relationships and unhealthy family functioning among primary schoolchildren. There was no clear relationship between poor teacher-pupil relationships and non-exclusionary absence or parental psychopathology in either age group.

\section{Discussion}

\section{Substantive findings}

It is reassuring that the majority of parents reported no concerns about the relationship between their child and their teacher, however, nearly 1 in 20 parents responded 'a lot' when asked whether their child had been stressed because s/he feels s/he has been unfairly picked on by a teacher. The proportion of parents reporting problematic teacher-pupil relationships increased significantly with the age of the child, which may reflect the difference in organisation between primary and secondary schools. Older children have to make relationships with a greater number of teachers but spend less time with each of them, which may provide increased opportunities for difficulties, and diminish the length of time available for the pupil-teacher dyad to build a good relationship. Spending smaller amounts of time with a teacher with whom you have a problematic relationship might be expected to reduce any negative impact of such contact. Our findings, however, suggest a clear association between poor teacher-pupil relationships and the presence of psychiatric disorder at secondary-school age as well as primary-school age: effects that mostly remain significant when adjusted for a range of confounding factors. These results suggest that a difficult relationship with a teacher may be highly detrimental to a child's well-being, and may actually precipitate behavioural problems in some young people. Although this may seem intuitively plausible, the research literature is littered with examples of intuitively plausible associations that did not stand up to empirical testing, and our study is one of very few to explore the relationship of teacher-pupil relationships with psychiatric disorder rather than dimensional measures of distress. It is deeply concerning that the likelihood of school exclusion may be significantly higher among young people whose parents report a problematic teacher-pupil relationship at a secondary-school age. Childhood psychiatric disorder and exclusion from school are associated with a range of adverse outcomes for individuals and substantial costs to society. ${ }^{29}$ At a primary-school age and before adjusting for baseline SDQ total difficulties score in addition to baseline psychiatric disorder, a problematic teacher-pupil relationship was related to poorer family functioning. This effect does not continue for secondary-school pupils, possibly because these children are more independent and there are fewer opportunities for direct contact between parents and teachers during these years, or that the smaller, more closed, primary-school community magnifies the impact of a challenging teacher-pupil relationship on the family.

\section{Methodological considerations}

We used data from a large nationally representative survey that involved children attending many different schools, adjusted for many background characteristics and studied psychiatric disorder. ${ }^{22}$ In contrast, previous research mostly focuses on teacher perspectives, often with more detail, but in much smaller

\begin{tabular}{|c|c|c|c|c|}
\hline Outcome & $\begin{array}{l}\text { Primary-school pupils } \\
\qquad(n=2733)\end{array}$ & $\begin{array}{l}\text { Secondary-school pupils } \\
\qquad(n=2593)\end{array}$ & $\begin{array}{l}\text { Total sample } \\
\quad(n=5326)\end{array}$ & $\begin{array}{l}\text { Number } \\
\text { with data }\end{array}$ \\
\hline Parental SDQ total difficulties score, mean (s.e.) & $8.04(0.12)$ & $7.06(0.12)$ & $7.57(0.08)$ & 5280 \\
\hline Any psychiatric disorder, $n(\%)$ & $229(8.4)$ & $253(9.6)$ & $482(9.0)$ & 5326 \\
\hline Any conduct disorder, $n(\%)$ & $126(4.6)$ & $108(4.1)$ & $234(4.4)$ & 5326 \\
\hline Exclusion from school, $n(\%)$ & $69(2.5)$ & $114(8.1)$ & $183(4.4)$ & 4102 \\
\hline Non-exclusionary absence in days, mean (s.e.) & $3.75(0.19)$ & $5.07(0.22)$ & $4.37(0.15)$ & 4142 \\
\hline Family function, mean FaLQ score (s.e.) & & & & 5234 \\
\hline Affirmation & $10.1(0.03)$ & $9.57(0.04)$ & $9.85(0.03)$ & \\
\hline Discipline & $2.94(0.03)$ & $2.20(0.03)$ & $2.58(0.02)$ & \\
\hline Rules & $4.30(0.03)$ & $3.95(0.03)$ & $4.13(0.02)$ & \\
\hline Special allowances & $2.96(0.03)$ & $2.90(0.03)$ & $2.93(0.02)$ & \\
\hline
\end{tabular}




\begin{tabular}{|c|c|c|c|c|}
\hline Outcome & $\begin{array}{l}\text { No/a little, } \\
\text { OR }\end{array}$ & $\begin{array}{l}\text { A lot without controlling for } \\
\text { baseline SDQ score, OR }(95 \% \mathrm{Cl})\end{array}$ & $\begin{array}{l}\text { A lot controlling for baseline } \\
\text { SDQ score, OR }(95 \% \mathrm{Cl})\end{array}$ & $n$ \\
\hline \multicolumn{5}{|l|}{ Any psychiatric disorder } \\
\hline Controlling for baseline psychiatric disorder & 1.00 & $4.25(2.20$ to 8.22$)$ & 2.55 (1.20 to 5.45$)$ & 2495 \\
\hline Excluding those with any baseline psychiatric disorder & 1.00 & $2.78(1.13$ to 6.80$)$ & 1.69 (0.63 to 4.51$)$ & 2335 \\
\hline \multicolumn{5}{|l|}{ Any conduct/behavioural disorder } \\
\hline Controlling for baseline conduct/behavioural disorder & 1.00 & $2.62(1.08$ to 6.34$)$ & $1.52(0.58$ to 3.97$)$ & 2495 \\
\hline Excluding those with any baseline conduct/behavioural disorder & 1.00 & $3.27(1.08$ to 9.89$)$ & $2.01(0.66$ to 6.14$)$ & 2407 \\
\hline Exclusion, excluding those with history of exclusion at baseline & 1.00 & $1.85(0.54$ to 6.31$)$ & $1.18(0.36$ to 3.89$)$ & 2456 \\
\hline Non-exclusionary absence, outcome is $>10$ days absence & 1.00 & $1.43(0.34$ to 6.00$)$ & 1.57 (0.39 to 6.31) & 2459 \\
\hline \multicolumn{5}{|l|}{ Parent psychopathology, linear regression } \\
\hline Control for baseline parental GHQ & - & $1.35(0.38$ to 2.31$)$ & $1.08(0.09$ to 2.06$)$ & 2473 \\
\hline Omit those with baseline $\mathrm{GHQ}>0$ & - & $1.54(0.11$ to 2.97$)$ & $1.38(-0.02$ to 2.79$)$ & 1442 \\
\hline $\begin{array}{l}\text { Family function, total FaLQ score controlled } \\
\text { for baseline McMasters score, linear regression }\end{array}$ & - & $2.17(1.17$ to 3.17$)$ & 1.83 (0.83 to 2.84) & 2448 \\
\hline $\begin{array}{l}\text { SDQ, Strengths and Difficulties Questionnaires; GHQ, General Health Questionne } \\
\text { a. All models were adjusted for gender; age; household income (grouped); hou } \\
\text { (dichotomised); learning disability (none, borderline, moderate/severe); social a }\end{array}$ & FaLQ, Family & $\begin{array}{l}\text { Life Questionnaire. } \\
\text { ed); mother's highest qualification; parent } \\
\text { n bold are significant. }\end{array}$ & baseline GHQ-12 score; general h & \\
\hline
\end{tabular}

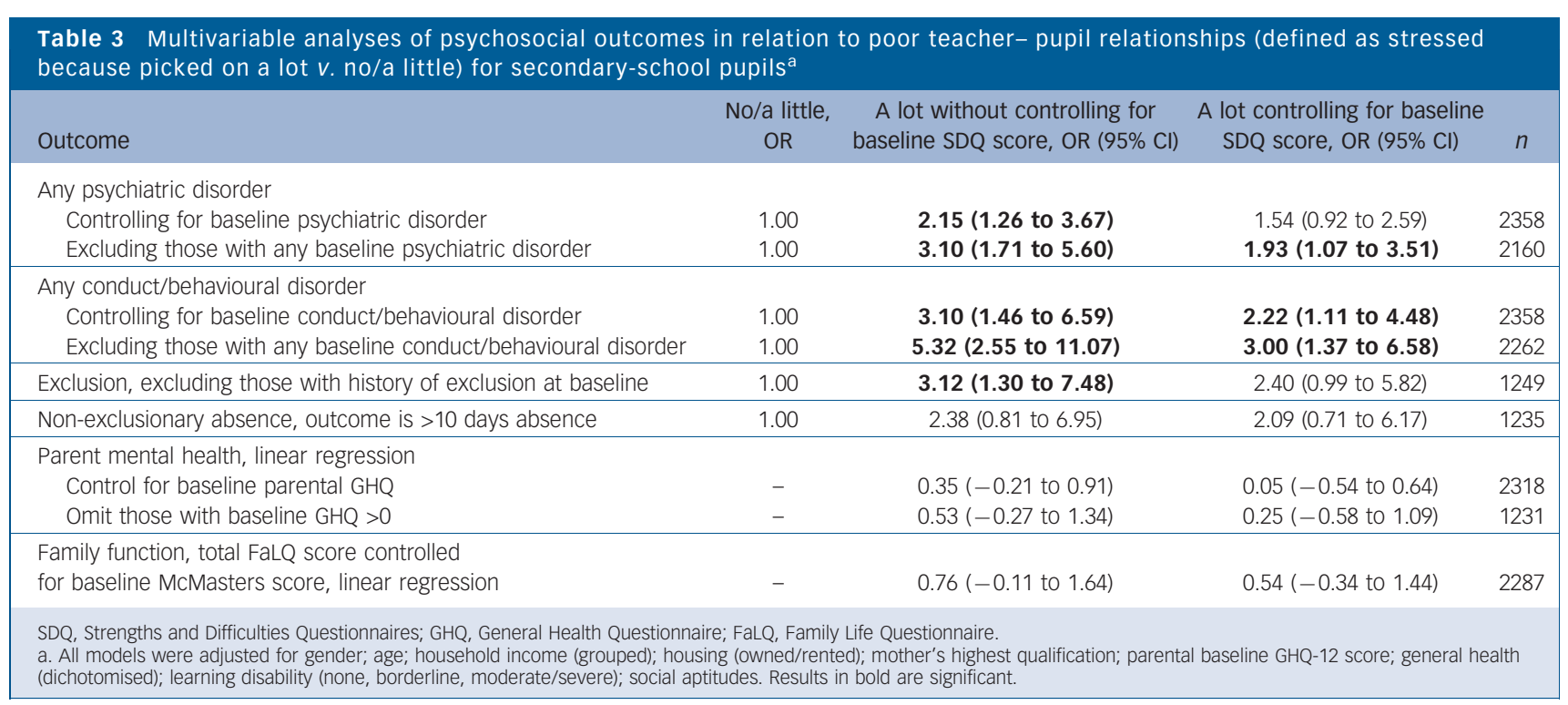

samples from a smaller number of schools and with dimensional measures of psychopathology. The current study also extends the literature through the use of parent-reports of the teacher-pupil relationships. We have no information on which to judge the veracity of these reports, and are aware that relatively low levels of inter-informant agreement are common in child mental health studies. ${ }^{30}$ In a population-based sample, the desire to locate difficulties in school to avoid guilt/blame that practitioners' may face with parents in the clinic is arguably less likely to influence reporting. There is, to our knowledge, no validated measure that we could have used on such a large scale, but it would be helpful for future studies if researchers could develop standardised methods for classifying and measuring teacher-pupil relationships to allow easier comparison of findings across studies. In the absence of such a measure, we have assumed that there are, on average, significant difficulties - whether in perception or reality - when parents answer 'a lot' to a question about whether their children have been stressed because they feel that they have been unfairly picked on by a teacher in the past year.

As a result of the design of the study, only children aged 11 or older contributed directly to the data, and not all parents consented to researcher contact with teachers. It is highly likely that a problematic teacher-pupil relationship would influence the decision to allow researcher access to school and that teachers would find it difficult to report problematic relationships. Thus, the decision to question parents about the teacher-pupil relationship provided the best opportunity to obtain data on as many children as possible. Both at baseline and follow-up, those, who according to our findings, would be most likely to have both the outcome (poor mental health) and the exposure (problematic teacher-pupil relationship) were less likely to participate. This suggests that we might have underestimated the prevalence of problems with relationships, although prior research in relation to the prevalence of disruptive behaviour suggests that this may not influence the pattern and/or size of the association. ${ }^{31}$

The limited literature on types of teacher-pupil relationships ${ }^{32}$ would benefit from attempts to classify relationships in terms of type and informant. Studies framed from pupils' perspectives have found both agreement and disparities between pupils' and teachers' accounts of the quality of teacher-pupil relationships. ${ }^{33}$ The best way to objectively assess this conflict also needs to be 
addressed as observations are unlikely to be effective because of social desirability.

As the study was a cross-sectional survey with a single follow-up and did not follow children from their entry to school, it is possible that a problematic teacher-pupil relationship is a marker of other difficulties that lead to the outcomes studied, rather than a causal factor. Further research in a cohort study that systematically assessed teacher-pupil relationships from school entry could address this issue.

Given the potential of these findings to distress teachers, we thought it important to adjust for both the presence of baseline psychiatric disorders and baseline psychopathology, which might not reach the threshold to meet diagnostic criteria but which may be related to both subsequent psychopathology and a problematic teacher-pupil relationship. Children were assessed in the middle of the school year (spring and early summer term) so a problematic relationship at baseline might also have influenced psychopathology at the time of baseline assessment. As some may consider that we have overadjusted, we present the results with four ways of adjusting for baseline psychopathology. We believe that the influence of poor teacher-pupil relationship on psychopathology, exclusion and family function probably lies between the results of the model with the highest (excluding children with baseline psychiatric disorder and adjusting for baseline SDQ total difficulties score) and lowest (controlling for baseline psychiatric disorder alone) level of adjustment.

As this was a secondary analysis, we were constrained by the variables collected in the original survey. We did not know the ethnicity of teachers as prior research suggests that teacher-pupil ethnic differences may influence teacher-pupil relationships. ${ }^{4,14}$ We also did not have access to teacher's reports of the teacherpupil relationship or the impact of problematic relationships on teachers' mental health and well-being. Adverse impacts on teachers, particularly if it leads to time off work or exit from the profession, represent further costs to both individuals and society. Similarly, we had no access to community- and school-level data; previous work suggests that the impact of teacher-pupil relationships might be particularly influential for children living in highly deprived circumstance ${ }^{4,6}$ and/or attending particularly well- or poorly functioning schools. ${ }^{34}$ We were, however, able to adjust for a wide range of potential confounders. The limited literature on types of teacher-pupil relationships ${ }^{32}$ would benefit from attempts to classify relationships in terms of type and informant. Studies framed from pupils' perspectives have found both agreement and disparities between pupils' and teachers' accounts of the quality of teacher-pupil relationship. ${ }^{33}$ The best way to objectively assess conflicting reports also needs to be addressed as observations are unlikely to be effective because of social desirability.

\section{Implications for policy and practice}

Little explicit attention has been paid to the importance of teacher-pupil relationships despite an increasing policy focus in the UK over the previous 10-15 years on the use of school setting for the promotion of mental health and well-being. ${ }^{35}$ The Targeted Mental Health in Schools (TAMHS) project aimed to support schools to deliver timely support to children and young people with mental health problems and those at high risk of developing them, with a particular emphasis on evidence-based practice and interagency working. ${ }^{36}$ Schools selected a wide variety of interventions and support; over 500 are named in the national evaluation, but training for staff was not commonly adopted and input related to teacher-pupil relationships was implicit rather than explicit. ${ }^{36}$ Social and Emotional Aspects of Learning (SEAL) was a 'comprehensive, whole-school approach to promoting the social and emotional skills that underpin effective learning, positive behaviour, regular attendance, staff effectiveness and the emotional health and well-being of all who learn and work in schools' in England during the past decade. ${ }^{37}$ The national evaluation of SEAL in secondary schools revealed a very mixed picture in terms of how SEAL was implemented and the impact of the initiative across participating schools, particularly in relation to a 'whole school approach' with staff 'will and skill' and resources seeming to predict progress and success. ${ }^{37}$ Both the TAMHS and SEAL evaluations called for greater attention to the evidence base for programmes that are adopted into schools, and a recent 'review of reviews' of mental health interventions in schools reported that large-scale, multicomponent whole school programmes that rely on broad principles rather than focused manualised interventions are unlikely to be effectively implemented. ${ }^{35}$ Most interventions in this review of reviews focused primarily on increasing pupil's life skills, but a 'positive school ethos' and the nature of teacher-pupil interactions was reported to be a major determinant of the impact of mental health interventions in school. ${ }^{35}$

Our findings add to the evidence that a difficult teacher-pupil relationship may have a wide-ranging negative impact on a child's development, specifically in relation to mental health and wellbeing, family function and exclusion from school. Previous research has highlighted factors that may contribute to this and therefore offers ideas as to where we can intervene to reduce the likelihood and/or impact of a problematic relationship. Considering the school environment, for instance, levels of conflict in relationships in kindergarten were associated with teachers' reported workload stress, and the broader relational climate in the classroom and school. ${ }^{38}$ In high-school pupils, conflictual teacher-pupil relationships were more commonly experienced by teachers who took a custodial approach to discipline, and had lower morale because of school conditions. ${ }^{38}$ Higher levels of conflict than expected based on children's behaviour were recorded by teachers who reported higher levels of depression and lower self-efficacy and in those observed to provide less emotional support in the classroom. ${ }^{16}$ KhouryKassabri ${ }^{19}$ suggests that many school staff react harshly to pupils because they lack alternative ways of dealing with difficulties, particularly when pupils are disruptive. Interventions that promote a positive school environment, increase teachers' classroom management skills and address teacher stress and burnout may therefore reduce the likelihood and/or impact of a problematic teacher-pupil relationship. Interventions that successfully improve these relationships have the potential to influence the mental health and academic outcome of all children subsequently taught by that teacher, and are therefore likely to be less costly than interventions aimed at children, which will need to be repeated with subsequent cohorts of children. In addition, parents who had adverse experiences in school may find it particularly difficult to trust and develop positive relationships with teachers; ${ }^{4}$ a focus on building relationships and easing communication may be an important but simple strategy to support the most vulnerable families in this respect. ${ }^{35}$

Although these interventions are focused on the education system, mental health is often not perceived to be 'core business' by education professionals. ${ }^{39}$ Our findings have clear public health implications and mental health practitioners may be in a position to influence commissioners and providers to consider interventions that could support teachers and other school-based staff to build more positive relationships that might produce important benefits extending far wider than the education system.

Although the call for increased support for teachers in relation to managing behaviour and promoting mental health and well-being 
is not novel, many teachers still feel insufficiently trained in relation to mental health and classroom management techniques, which may contribute to work-related stress and burnout as well as poor teacher-pupil relationships. ${ }^{2}$ Some children and parents may be extremely difficult to work with, but if there is a difficulty in the relationship the teacher has with a particular child or family, then the professional responsibility to address it lies with the teacher, and the school's senior management team has a duty to support the teacher to do so. The current study suggests that effective strategies to improve teacher-pupil relationships may reduce the negative outcomes for pupils that are associated with these poor relationships, as well as reducing burnout and stress among teachers. A more explicit focus on the quality of teacher-pupil relationships in research, policy and practice in relation to mental health in schools may improve the impact of other interventions.

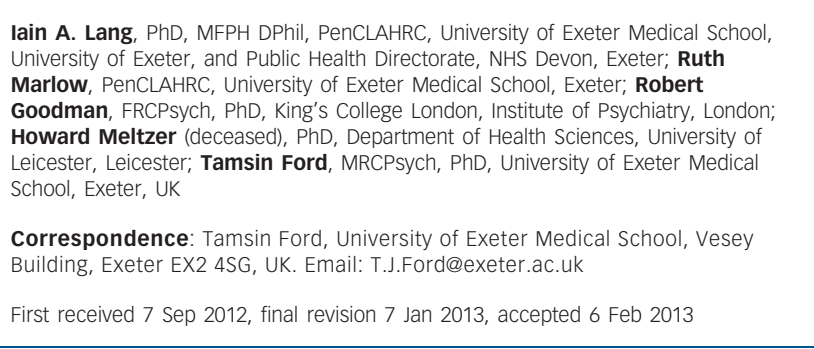

\section{Funding}

The original morbidity studies were funded by the English Department for Health and the Scottish Office and led by the Office for National Statistics (H.M.) and the Institute of Psychiatry, Kings College London (R.G.). R.M. and I.A.L. completed this work while supported by the National Institute for Health Research (NIHR) Collaboration for Leadership in Applied Health Research and Care (CLAHRC) for the South West.

\section{References}

1 Dumont M, Provost MA. Resilience in adolescents: protective role of social support, coping strategies, self-esteem, and social activities on experience of stress and depression. J Youth Adolesc 1999; 28: 343-63.

2 Kokkinos CM. Job stressors, personality and burnout in primary school teachers. Br J Educ Psychol 2007; 77: 229-43.

3 Pianta RC, Steinberg MS, Rollins KB. The first two years of school: teacher-child relationships and deflections in children's classroom adjustment. Dev Psychopathol 1995; 7: 295-312.

4 Hughes J, Kwok OM. Influence of student-teacher and parent-teacher relationships on lower achieving readers' engagement and achievement in the primary grades. J Educ Psychol 2007; 99: 39-51.

5 Rudasill KM, Reio TG, Stipanovic N, Taylor JE. A longitudinal study of studentteacher relationship quality, difficult temperament and risky behaviour from childhood to early adolescence. J Sch Psychol 2010; 48: 389-412.

6 Hamre BK, Pianta RC. Can instructional and emotional support in the firstgrade classroom make a difference for children at risk of school failure? Child Dev 2005; 76: 949-67.

7 Ystgaard M. Life stress, social support and psychological distress in late adolescence. Soc Psychiatry Psychiatr Epidemiol 1997; 32: 277-83.

8 Ladd GW, Birch SH, Buhs ES. Children's social and scholastic lives in kindergarten: related spheres of influence? Child Dev 1999; 70: 1373-400.

9 Buyse E, Verschueren K, Verachtert P, Van Damme J. Predicting school adjustment in early elementary school: impact of teacher-child relationship quality and relational classroom climate. Elem Sch J 2009; 110: 119-41.

10 Cadima J, Leal T, Burchinal M. The quality of teacher-student interactions: associations with first graders' academic and behavioural outcomes. J Sch Psychol 2010; 48: 457-82.

11 Murray C, Murray KM. Child level correlates of teacher-student relationships: an examination of demographic characteristics, academic orientations, and behavioural orientations. Psychol Sch 2004; 41: 751-62.

12 Thijs JT, Koomen HMY, Leij van der A. Teacher-child relationships and pedagogical practices: considering the teacher's perspective. Sch Psychol Rev 2008; 37: 244-60.

13 Koepke MF, Harkins DA. Conflict in the classroom: gender differences in the teacher-child relationships. Early Educ Dev 2008; 19: 843-64.
14 Murray C, Murray KM. Child level correlates of teacher-student relationships: an examination of child demographic characteristics, academic orientations, and behavioural orientations. Psychol Sch 2004; 41: 751-62.

15 Blacher J, Baker BL, Eisenhower AS. Student-teacher relationship stability across early school years for children with intellectual disability or typical development. Am J Intellect Dev Disabil 2009; 114: 322-39.

16 Hamre BK, Pianta RC, Downer JT, Mashburn AJ. Teachers' perceptions of conflict with young students: looking beyond problem behaviours. Soc Dev 2008; 17: 115-36.

17 Solberg M, Olweus D. Prevalence estimation of school bullying with the Olweus Bully/Victim Questionnaire. Aggress Behav 2003; 29: 239-68.

18 Delfabbro P, Winefield T, Trainor S, Dollard M, Anderson S, Metzer J, Hammarstrom A. Peer and teacher bullying/victimization of South Australian secondary school students: prevalence and psychosocial profiles. Br J EduC Psychol 2006; 76: 71-90.

19 Khoury-Kassabri M. The relationship between staff maltreatment of students and bully-victim group membership. Child Abuse Neg/ 2009; 33: 914-23.

20 Piekarska A. School stress, teachers' abusive behaviours, and children's coping strategies. Child Abuse Negl 2000; 24: 1443-9.

21 Whitted KS, Dupper DR. Do teachers bully students? Findings from a survey of students in an alternative education setting. Educ Urban Soc 2008; 40 : 329-41.

22 Green H, McGinnity A, Meltzer H, Ford T, Goodman R. Mental Health of Children and Young People in Great Britain 2004. Palgrave Macmillan, 2005.

23 Goodman R, Ford T, Richards H, Gatward R, Meltzer H. The Development And Well-Being Assessment: description and initial validation of an integrated assessment of child and adolescent psychopathology. J Child Psychol Psychiatry 2000; 41: 645-55.

24 American Psychiatric Association. Diagnostic and Statistical Manual of Mental Disorders (4th edn) (DSM-IV). APA, 1994.

25 Goodman R, Scott S. Comparing the Strengths and Difficulties Questionnaire and the Child Behaviour Checklist: is small beautiful? J Abnorm Child Psych 1999; 27: 17-24.

26 Epstein NB, Baldwin LM, Bishop DS. The McMaster family Assessment Device. J Marital Fam Ther 1983; 9: 171-80.

27 Last A, Miles R, Wills L, Brownhill L, Ford T. The reliability and sensitivity to change of the Family Life Questionnaire. Child Adolesc Ment Health 2012; 17: $121-5$.

28 Goldberg D, Williams P. GHQ: A User's Guide to the General Health Questionnaire. nferNelson, 1988.

29 Scott S, Knapp M, Henderson J, Maughan B. Financial costs of social exclusion: follow up study of antisocial children into adulthood. BMJ 2001; 323: 1-5.

30 Collishaw S, Goodman R, Ford T, Rabe-Hesketh S, Pickles A. How far are associations between child, family and community factors and child psychopathology informant-specific and informant-general? J Child Psychol Psychiatry 2009; 50; 571-80.

31 Wolke D, Waylen A, Samara M, Steer C, Goodman R, Ford T, et al. Does selective drop out lead to biased prediction of behaviour disorders. Br J Psychiatry 2009; 195: 249-56.

32 Wu JY, Hughes JN, Kwok OM. Teacher-student relationship quality type in elementary grades: effects on trajectories for achievement and engagement. J Sch Psychol 2010; 48: 257-387.

33 Murray C, Murray KM, Waas GA. Child and teacher reports of teacherstudent relationships: concordance of perspectives and associations with school adjustment in urban kindergarten classrooms. J Appl Dev Psychol 2008; 29: 49-61.

34 Mantzicopoulos P. Conflictual relationships between kindergarten children and their teachers: associations with child and classroom context variables. J Sch Psychol 2005; 43: 425-42.

35 Weare K, Nind M. Promoting the Mental Health Of Children and Adolescents through Schools and School-Based Interventions: Report of Work Package 3 of the DATAPREV Project. University of Southampton School of Education, 2011.

36 Department for Education. Me and My School: Findings from the National Evaluation of Targeted Mental Health in Schools 2008-11. Research Report DFE-RR177. Department for Education, 2011.

37 Humphrey N, Lendrum A, Wigelsworth M. Social Emotional Aspects of Learning (SEAL) Programme in Secondary Schools: National Evaluation. Research Report DFE RR049. Department for Education, 2011.

38 Sava FA. Causes and effects of teacher conflict-inducing attitudes towards pupils: a path analysis model. Teach Educ 2002; 18: 1007-21.

39 Kidger J, Gunnell D, Biddle L, Campbell R, Donovan J. Part and parcel of teaching? Secondary school staff's views on supporting student emotional health and well-being. Br Educ Res J 2010; 36: 919-35. 